\title{
The Negligible Effect of Metformin Addition to Letrozole in Treating Overweight Women with PCOS
}

\section{Mohamed Nabih EL-Gharib*, Mona Tawfeek EL-Ebiary, Manal Abdel Raoof Farahat}

Department of Obstetrics and Gynecology, Tanta University, Egypt

Correspondence to: Mohamed Nabih EL-Gharib, Department of Obstetrics and Gynecology, Tanta University, Egypt; E-mail: mohamed.el-gharib@med.tanta.edu. eg

Received date: September 21, 2020; Accepted date: September 30, 2020; Published date: October 7, 2020

Citation: EL-Gharib MN, EL-Ebiary MT, Raoof Farahat MA (2020) The Negligible Effect of Metformin Addition to Letrozole in Treating Overweight Women with PCOS. J Obst Gynecol Surg 1(2): pp. 1-6.

Copyright:@2020 EL-Gharib MN, et al. This is an open-access article distributed under the terms of the Creative Commons Attribution License, which permits unrestricted use, distribution and reproduction in any medium, provided the original author and source are credited

\section{ABSTRACT}

Aim: To compare the effects of letrozole alone and letrozole plus metformin on ovulation induction, endometrial thickness, number of ovarian follicles and, the pregnancy rate in overweight, infertile women with the polycystic ovarian syndrome.

Study design: Prospective, randomized clinical trial.

Material and methods: This study was conducted on 120 patients with polycystic ovarian syndrome, recruited from the infertility clinic of Tanta University Hospital, January 2017 to December 2019. Sixty women were assigned at random to each group. In a group, 1 patient received only daily $5 \mathrm{mg}$ letrozole between days 3 and 7 of the menstrual cycle, and in group 2, continuous metformin was used at the dose of $500 \mathrm{mg} / \mathrm{TDS} /$ day for three months; afterward, daily $5 \mathrm{mg}$ letrozole between 3 and 7 days of the menstrual cycle was added to the metformin therapy. The patients were treated until pregnancy occurred, or three cycles were reached without pregnancy.

Results: There was an insignificant increase in the cumulative pregnancy rate between the metformin-letrazole and the letrazole group. In the metformin-letrozole group, $28.33 \%$ of the patents got pregnant, compared with $25 \%$ of the patients in the letrazole group. There was no significant difference between the letrazole and the metforminletrazole group regarding ovulation rate, number of the follicle, endometrial thickness, and progesterone level.

Conclusion: The addition of metformin to letrazole does not improve the outcome of overweight PCOS women.

\section{Keywords:}

Letrozole, Metformin, PCOS, Overweight.

\section{Introduction}

Polycystic Ovary Disorder (PCOS) is a huge medical issue. PCOS is probably the most reason that influences the ladies of childbearing age, [1] and regularly prompts barrenness [2]. The research proposes that $5 \%$ to $10 \%$ of females 18 to 44 years old are influenced by PCOS, making it the most well-known endocrine irregularity among ladies of regenerative age in the U.S [3]. Different administrations proposed for fruitless ladies with PCOS. Be that as it may, the ideal administration choice has not tended to fulfill [4].

Aromatase, a compound containing cytochrome P450 hemoprotein, catalyzes the change of androstenedione and testosterone to estrogen. The ovarian aromatase is delivered in wealth in ladies during the regenerative stage since ovaries are a significant site for the creation of estrogen [5] The thirdage aromatase inhibitors like letrozole are profoundly powerful, with a 97-99\% decrease in estrogen levels [6].

Letrozole is a particular aromatase inhibitor. It hinders estrogen creation by quelling the protein aromatase [7]. Letrozole diminishes estrogen creation without influencing estrogen receptors, decreases the negative criticism on the nerve center and pituitary, and animates FSH discharge [8]. Letrozole is additionally cleared from the flow all the more quickly because of a shorter half-life, 48 hours when contrasted with clomiphene citrate, which may take as long as two months because of its drawn-out half-life, two weeks [9]. The present bits of proof recommend that letrozole can put as first-line treatment for the administration of barrenness due to PCOS and unexplained fruitlessness [10].

Metformin is a biguanide that brings down blood glucose levels in hyperglycemic people with type-2 diabetes mellitus yet has no impact on glucose levels in ordinary subjects [11]. Metformin is right now the primary line oral treatment for the administration of type 2 diabetes [12]. Other helpful impacts of metformin were uncovered, such as the hindrance of tumors, postponing maturing, and immunomodulation [13]. The focal point of the component of the activity of metformin is the metabolic modification of the cell vitality [14]. Metformin applies its overwhelming impact in diminishing glucose by the reuptake of insulin-invigorated glucose in skeletal muscles, reduced generation of hepatic glucose, and decreased intestinal glucose assimilation [14,15].

Numerous uncontrolled and some controlled studies showed that metformin diminished insulin obstruction in ladies with PCOS and improved the probability of ovulation and pregnancy without, or some of the time with, clomiphene citrate $[16,17]$. However, the specific job of metformin in the administration of ladies with PCOS has been very dubious [18]. Several investigations have indicated a good job of metformin in PCOS patients by expanding pregnancy rate and improving the metabolic circumstance [19-21].

This study aims to compare the effect of administration of letrozole versus combined metformin-letrozole in the induction 
Citation: EL-Gharib MN, EL-Ebiary MT, Raoof Farahat MA (2020) The Negligible Effect of Metformin Addition to Letrozole in Treating Overweight Women with PCOS. J Obst Gynecol Surg 1(2): pp. 1-6.

of ovulation in overweight, infertile women with PCOS.

\section{Patients and Methods}

This prospective randomized study was conducted at the Department of Obstetrics \& Gynecology at Tanta University Hospital from January 2017 to December 2019 to treat infertility.

\section{Subjects}

The study included 120 overweight women with BMI 25-30, complaining of polycystic ovary syndrome and attending the infertility outpatient clinic of Tanta University Hospital. All women involved in the study gave written informed consent after proper counselling.

\section{Inclusion criteria}

All patients fulfilled the following inclusion criteria:

- Age 18-30 years.

- Polycystic ovarian syndrome women according to Rotterdam Criteria 2003 [22]

- Standard parameters of the husband's semen

\section{Exclusion criteria}

- $\quad$ Patients with a history of cardiovascular disease, diabetes or liver, and kidney failure were excluded

- Similarly, patients whose partner sperm count was less than 20 million/ $\mathrm{ml}$ and sperm motility less than $20 \%$ were also not included

- Patients who had undergone surgical treatment of infertility

- Recent history of ovulatory inducing drugs within the last 3 months

- $\quad$ Patients are diabetic mellitus or any systemic disease

The patients were divided randomly into two groups through a series of blind envelopes from 1 to 120 . Each patient was invited to pull out an envelope and was placed in either:

- Group A: Letrozole group (envelopes number 1-60)

- Group B: Metformin-Letrozole group (envelopes number 61-120)

\section{Methods}

Informed written consents were obtained from the patients participating in this study after informing them about the aims of the study, the steps of the study, drugs are given, and the capability to withdraw at any time.

\section{Patient preparation}

History taking including clinical examination, transvaginal ultrasound examination, estimation of serum progesterone on days $21-23$ of the cycle.

\section{Induction of ovulation}

All patients of both groups were received $5 \mathrm{mg}$ letrozole (Letrozole, Technopharma, Cairo, Egypt) for five days from 3rd day of their menstrual cycle. The condition of the ovaries was determined by transvaginal sonography every other day from the 10th of the cycle.

Patients of group B received $1500 \mathrm{mg}$ metformin $\mathrm{HCl}$ daily, $500 \mathrm{mg}$ three times a day (Cidophage; Chemical Industries Development, Cairo, Egypt).

The hCG hormone (a total of 10,000 IU IM, Choriamon; IBSA, Lugano, Switzerland) was given when one follicle measuring at least 18 was found. Patients advised having intercourse every other day for one week, starting 24-36 h after receiving HCG. The patients continued treatment for three successive cycles using the same protocol.

\section{Follow up}

Follicle monitoring and endometrial thickness measurement were done with the help of transvaginal sonography serially starting from the 6th day of the drug administration when at least one follicle reached maturity $(>18 \mathrm{~mm})$. Confirmation of the pregnancy was done through a urine test using a pregnancy test kit and transvaginal sonography. After verification of pregnancy, these patients were followed up and treated as antenatal cases. Metformin continued until 28 weeks. The two groups were compared to each other regarding ovulation, evaluated by folliculometry and progesterone levels.

Statistical methods: The data were transferred to IBM cards using an IBM personal computer and analyzed with the Statistical Program for Social Sciences V11.0 (SPSS Inc, Chicago, IL). Descriptive statistics comprised the mean and Standard Deviation (SD). Analytical statistics constituted the student t-test to compare independent quantitative means, and the chi-square test $(\chi 2)$ to compare between the different groups concerning qualitative data. The chosen level of significance was $p<0.05$ in all studies. The $p$-value less than 0.05 was considered to be significant, and the confidence interval for the odds ratio was set at $95 \%$.

\section{Results}

There were no significant differences between both groups in age or duration of infertility (mean age was $28.54 \pm 3.13$ years and mean duration of infertility was $3.81 \pm 1.50$ years in the letrozole group and mean age was $29.55 \pm 3.47$ years and mean duration of infertility was $2.76 \pm 1.48$ years in the metforminletrozole group. As regards $\mathrm{BMI}$, the mean $\mathrm{BMI}$ was $28.98 \pm$ 3.83 in the letrazole group and $29.21 \pm 2.92$ in the metforminletrazole group, as displayed in Table 1.

Table 1: Comparison between the two studied groups according to the characteristics of the study population.

\begin{tabular}{|l|l|l|l|l|l|}
\hline \multirow{2}{*}{ Item } & Letrozole Group & \multicolumn{2}{l|}{ Letrozole_Metformin Group } & \multirow{2}{*}{ P-value } \\
\cline { 2 - 5 } & Mean & SD & Mean & SD & \\
\hline Age (years) & 28.54 & 3.13 & 29.55 & 3.47 & 0.21073 \\
\hline Duration of infertility (Y) & 3.81 & 1.5 & 2.76 & 1.48 & 0.55809 \\
\hline BMI (Kg/m2) & & & 29.21 & 2.92 & 0.99848 \\
\hline *: Statistically significant at $\mathrm{p} \leq 0.05$ & 28.98 & 3.83 & & \\
\hline
\end{tabular}

As regards the effect of treatment on ovulation: the letrazole group reported 36 cases $(60.00 \%)$ ovulation at the first cycle after treatment, increased to 48 patients $(78.33 \%)$ at the second cycle, and to 55 patients (91.66\%) at the third cycle. On the other hand, the Metformin-letrazole group reported 38 patients $(63.33 \%)$ ovulation at first cycle after treatment, which 
Citation: EL-Gharib MN, EL-Ebiary MT, Raoof Farahat MA (2020) The Negligible Effect of Metformin Addition to Letrozole in Treating Overweight Women with PCOS. J Obst Gynecol Surg 1(2): pp. 1-6.

increased to 50 cases (83.33\%) in the second cycle and 57 patients (95.00\%) at the end of the third cycle. Correspondingly, the letrazole group achieved a cumulative ovulation rate of

Table 2: Effect of treatment on ovulation in the studied groups.

\begin{tabular}{|l|l|l|l|l|l|}
\hline \multirow{2}{*}{ Item } & Letrozole Group & \multicolumn{2}{l|}{ Letrozole_Metformin Group } & \multirow{2}{*}{ P-value } \\
\cline { 2 - 5 } & $\mathrm{N}$ & $\%$ & $\mathrm{~N}$ & $\%$ & \\
\hline First Cycle & 36 & 60 & 38 & 63.33 & 0.7668 \\
\hline Second Cycle & 48 & 78.33 & 50 & 83.33 & 0.5313 \\
\hline Third Cycle & 55 & 91.66 & 57 & 95 & 0.4799 \\
\hline *: Statistically significant at $\mathrm{p} \leq 0.05$ & \multicolumn{4}{l}{} \\
\hline
\end{tabular}

Concerning the mean number of follicles in the ovaries of both groups after treatment, we found that in the letrazole group, the mean number of follicles was $1.34 \pm 0.53$ at the first cycle, elevated to be $1.38 \pm 0.76$ at the second cycle, and to $1.41 \pm$ 0.71 at the third cycle. In the metformin-letrazole group, the

mean number of follicles was $1.25 \pm 0.49$ in the first cycle, elevated to $1.32 \pm 0.72$ in the second cycle and $1.43 \pm 0.65$ at the third cycle. There was no statistical difference between the two studied groups, as represented in Table 3.

Table 3: Effect of treatment on the mean number of follicles.

\begin{tabular}{|c|c|c|c|c|c|c|c|}
\hline \multirow[t]{2}{*}{ No. of follicles } & \multicolumn{3}{|c|}{ Letrozole Group } & \multicolumn{3}{|c|}{ Letrozole_Metformin Group } & \multirow[t]{2}{*}{ P-value } \\
\hline & No. & Mean & SD & No. & Mean & SD & \\
\hline First Cycle & 36 & 1.34 & 0.53 & 37 & 1.25 & 0.49 & 0.3207 \\
\hline Second Cycle & 48 & 1.38 & 0.76 & 47 & 1.32 & 0.72 & 0.35621 \\
\hline Third Cycle & 52 & 1.41 & 0.71 & 54 & 1.43 & 0.65 & 0.73737 \\
\hline
\end{tabular}

In connection with the mean follicular diameter across, there is no factually huge distinction in mean follicular width (MFD) in the two groups. In the letrazole group, it was $17.04 \pm 1.09$ $\mathrm{mm}, 17.39 \pm 1.36 \mathrm{~mm}$, and $18.95 \pm 3.04 \mathrm{~mm}$ at the first, second, and third cycles, respectively, while in the metformin-letrazole

group, the corresponding values were $17.56 \pm 1.05 \mathrm{~mm}, 19.29 \pm$ $1.27 \mathrm{~mm}$ and $19.30 \pm 3.03 \mathrm{~mm}$ at first, second and third cycles respectively. There was an insignificant difference between both groups, as displayed in Table 4.

Table 4: Impact of treatment on the mean follicular width in studied groups.

\begin{tabular}{|l|l|l|l|l|l|}
\hline \multirow{2}{*}{ Mean follicular diameter } & Letrozole Group & \multicolumn{2}{l|}{ Letrozole_Metformin Group } & P-value \\
\cline { 2 - 6 } & Mean & SD & Mean & SD & \\
\hline First Cycle & 17.04 & 1.09 & 17.56 & 1.05 & 0.5831 \\
\hline Second Cycle & 17.39 & 1.36 & 18.29 & 1.27 & 0.73229 \\
\hline Third Cycle & 18.95 & 3.04 & 19.3 & 3.03 & 0.50952 \\
\hline *: Statistically significant at $p \leq 0.05$
\end{tabular}

Regarding the number of follicles $>18 \mathrm{~mm}$ in both groups, there was no statistically significant difference between studied groups. In the letrazole group, the average number of follicles measuring $>18 \mathrm{~mm}$ was $1.13 \pm 0.48,1.05 \pm 0.52$, and $1.14 \pm 0.55$ Table 5: Effect of treatment on the number of follicles $>18 \mathrm{~mm}$.

\begin{tabular}{|l|l|l|l|l|l|}
\hline \multirow{2}{*}{ No. of follicles $>18 \mathrm{~mm}$} & Letrozole Group & \multicolumn{2}{l|}{ Letrozole_Metformin Group } & P-value \\
\cline { 2 - 6 } & Mean & SD & Mean & SD & \\
\hline First Cycle & 1.13 & 0.48 & 1.01 & 0.46 & 0.5944 \\
\hline Second Cycle & 1.05 & 0.52 & 0.97 & 0.51 & 0.54808 \\
\hline Third Cycle & 1.14 & 0.55 & 1.22 & 0.45 & 0.92108 \\
\hline$*:$ Statistically significant at $\mathrm{p} \leq 0.05$ & &
\end{tabular}

Table 6, 6 illustrates that no statistically significant difference was found between letrazole and metformin-letrazole groups regarding the cumulative number of follicles and the aggregate number of mean follicular diameter. On the contrary, there was at first, second, and third cycles, respectively. In contrast, in the metformin-letrazole group, the equivalent values were $1.01 \pm$ $0.46,0.97 \pm 0.51$, and $1.22 \pm 0.45$, as shown in Table 5 . There was an insignificant difference between both groups.

a significant increase in the Metformin-letrazole group than letrazole group as regard Cumulative Endometrial thickness as displayed in Table 6. 
Citation: EL-Gharib MN, EL-Ebiary MT, Raoof Farahat MA (2020) The Negligible Effect of Metformin Addition to Letrozole in Treating Overweight Women with PCOS. J Obst Gynecol Surg 1(2): pp. 1-6.

Table 6: Effect of treatment on the cumulative number of follicles, mean follicular diameter, and endometrial thickness between the study groups.

\begin{tabular}{|l|l|l|l|l|l|}
\hline \multirow{2}{*}{ Item } & Letrozole Group & \multicolumn{2}{l|}{ Letrozole_Metformin Group } & \multirow{2}{*}{ P-value } \\
\cline { 2 - 5 } & Mean & SD & Mean & SD & \\
\hline Cum. No. of follicles & 1.59 & 0.55 & 1.55 & 0.53 & 0.59632 \\
\hline Cum. Mean follicular diameter & 18.03 & 2.76 & 18.52 & 2.95 & 0.33318 \\
\hline Cum no. of fol. $>18 \mathrm{~mm}$ & 1.32 & 0.47 & 1.36 & 0.38 & 0.99222 \\
\hline *: Statistically significant at $\mathrm{p} \leq 0.05$ &
\end{tabular}

The endometrium was thicker in the group accepting metformin-letrazole than in that getting letrazole (Table 7) on the day of human chorionic gonadotrophin administration. In the letrazole group, the endometrial thickness was $7.93 \pm 0.91$, $8.92 \pm 0.94$, and $9.33 \pm 0.95 \mathrm{~mm}$ at the first, second, and third

Table 7: Comparison between the two studied groups according to Endometrial Thickness on the day of HCG administration in the three months separately and Cumulative Endometrial thickness.

\begin{tabular}{|l|l|l|l|l|l|}
\hline \multirow{2}{*}{ Item } & Letrozole Group & \multicolumn{2}{l|}{ Letrozole_Metformin Group } & \multirow{2}{*}{ P-value } \\
\cline { 2 - 5 } & Mean & SD & Mean & SD & \\
\hline First Cycle & 7.93 & 0.91 & 7.82 & 0.79 & 0.21088 \\
\hline Second Cycle & 8.92 & 0.94 & 9.02 & 0.99 & 0.6351 \\
\hline Third Cycle & 9.33 & 0.95 & 9.34 & 1.03 & 0.74736 \\
\hline *: Statistically significant at $p \leq 0.05$ & & & \\
\hline
\end{tabular}

In connection with the progesterone level at the mid-luteal phase, we found an insignificant increase in progesterone levels in the metformin-letrazole group than the letrazole group. In the metformin-letrazole group, progesterone values were 8.73

$\pm 0.96,9.09 \pm 0.49$, and $9.59 \pm 0.62$ at the first, second, and third cycles, respectively, while in the letrazole group, the equivalent values were $8.58 \pm 0.90,8.97 \pm 0.73,9.39 \pm 0.70$ at first, second and third cycles respectively as revealed in Table 8 .

Table 8: Comparison between the Letrozole and Letrozole metformin groups according to serum progesterone $(\mathrm{ng} / \mathrm{ml}$ ) level.

\begin{tabular}{|l|l|l|l|l|l|}
\hline \multirow{2}{*}{ Progesterone (ng/ml) } & Letrozole Group & \multicolumn{2}{l|}{ Letrozole_Metformin Group } & \multirow{2}{*}{ P-value } \\
\cline { 2 - 5 } & Mean & SD & Mean & SD & \\
\hline First Cycle & 8.58 & 0.9 & 8.73 & 0.96 & 0.39068 \\
\hline Second Cycle & 8.97 & 0.73 & 9.09 & 0.49 & 0.9548 \\
\hline Third Cycle & 9.39 & 0.7 & 9.59 & 0.62 & 0.71979 \\
\hline *: Statistically significant at $\mathrm{p} \leq 0.05$ & \multicolumn{5}{l}{} \\
\hline
\end{tabular}

The menses were regular in $65 \%$ of patients in the letrazole group and $68.33 \%$ of the metformin-letrazole group. Side effects as gastritis and sickness happened in $5 \%$ of patients in letrazole and $8.33 \%$ of metformin-letrazole groups. Regarding pregnancy rate (per cycle) in the letrazole and metformin-letrazole groups, there was no critical distinction between the pregnancy rates per cycle in the letrazole and the metformin-letrazole gatherings $(\chi 2=0.045$ and $P=0.8323)$. The cumulative pregnancy rate in the letrazole group was $25.00 \%$ versus $28.33 \%$ for the metformin-letrazole group. In the letrazole group, three cases got pregnant in the first month; six cases got pregnancy within the second and third months, respectively. The corresponding figure relating to the metformin-letrazole group were three, seven, and eight cases got pregnancy within the first, second, and third months respectively.

\section{Discussion and Conclusion}

The high predominance of PCOS in ladies and its fruitlessness results has prompted various studies focusing on new medications with fewer or no reactions. Letrozole-metformin is a broadly suggested substitute that can animate FSH discharge and ovarian follicular improvement [23]. Overweight (BMI $\geq$
$25 \mathrm{~kg} / \mathrm{m} 2$ ) is associated with an all-encompassing danger of anovulatory barrenness [24]. This examination was performed to research the impacts of letrozole-metformin versus letrozole alone in the administration of overweight ladies having PCOS.

The consequences of this examination demonstrate that overweight ladies with PCOS experienced an unimportant higher pregnancy rate when they got metformin in addition to letrozole in correlation with in addition to letrazole alone. In our present investigation, we found that the aggregate pregnancy rate in the letrazole bunch was $25.00 \%$ versus $28.33 \%$ for the metformin-letrazole bunch in the letrazole gathering. This considers the aftereffects of Hurley et al. They reported that the expansion of metformin during ovulation acceptance with letrozole does not influence pregnancy result in fruitless ladies with polycystic ovary disorder [25].

As respects the adequacy of letrozole, our outcomes are similar to that found by Elnashar et al. [26], Badawy et al. [27], and Nupur et al. [28] studies in which pregnancy/cycle, with letrazole, were $13.6 \%, 12.2 \%$, and $14.2 \%$ individually. Mitwally and Casper [29], Al-Omari et al. [30], Atay et al. [31], and Begum et al. [32] in which pregnancy/cycle were $17.5 \%, 25 \%, 19 \%$, and 
Citation: EL-Gharib MN, EL-Ebiary MT, Raoof Farahat MA (2020) The Negligible Effect of Metformin Addition to Letrozole in Treating Overweight Women with PCOS. J Obst Gynecol Surg 1(2): pp. 1-6.

$15.1 \%$ separately. Sohrabvand et al. detailed that the pregnancy rate in the metformin-letrazole bunch was 34.5\% [33]. Multiple randomized preliminaries inspecting clinical pregnancy rates in patients treated with metformin versus fake treatment are underpowered and neglect to distinguish any improvement with metformin [34-39].

Our results disprove those of Rabia Mohsin et al., who found a high pregnancy rate in patients getting letrozole in addition to metformin versus letrozole alone [40]. Liu et al. revealed a pregnancy pace of $57.9 \%$ in letrozole in addition to metformin gathering and just $46.8 \%$ in patients who got letrozole alone [41]. Another examination directed by Elgafore et al. revealed that letrazole, in addition to metformin blend, can have a triumph pace of $90.57 \%$ and fruitful pregnancy in $34.50 \%$ females [42].

While Davar et al. announced a pregnancy pace of just $8.3 \%$ in PCOS ladies, these creators found a very lower speed of pregnancy acceptance after letrozole and metformin mix [43]. No critical connection between age, BMI, or term of fruitlessness, the pace of ovulation, number of follicles, or endometrial thickness seen in both examined gatherings.

Only one RCT in anovulatory ladies with PCOS and a weight file (BMI) $>32 \mathrm{~kg} / \mathrm{m} 2$ (got metformin or fake treatment) and $\leq 32$ $\mathrm{kg} / \mathrm{m} 2$ (acquired CC, metformin, or both) announced live-birth rates. This preliminary found no factually noteworthy distinction, detailing a live-birth pace of $16 \%$ (5/32) with metformin and $6 \%$ $(2 / 33)$ with fake treatment in ladies with $\mathrm{BMI}>32 \mathrm{~kg} / \mathrm{m} 2$. For ladies with a BMI $\leq 32 \mathrm{~kg} / \mathrm{m} 2$, there is no proof of considerable contrasts in results whether treated with metformin CC or both [44].

Lastly, we conclude that the expansion of metformin to letrazole does not improve the overweight PCOS ladies.

\section{Conflicts of Interest}

The authors declare that there is no conflict of interest.

\section{Funding Statement}

\section{$\mathrm{N} / \mathrm{A}$}

\section{References}

1. Meier RK (2018) Polycystic ovary syndrome. Nurs Clin North Am 53(3):407-420.

2. Tanbo T, Mellembakken J, Bjercke S, et al. (2018) Ovulation induction in polycystic ovary syndrome. Acta Obstet Gynecol Scand 97(10): pp.1162-1167.

3. National Institutes of Health, Department of Health and Human Services. Beyond Infertility: Polycystic Ovary Syndrome (PCOS). NIH Pub. No. 08-5863, April 2008.

4. Guang H, Li F, Shi J (2018) Letrozole for patients with polycystic ovary syndrome. Medicine 97(44): e13038

5. Karaer O, Oruc S, Koyuncu FM (2004) Aromatase inhibitors: possible future applications. Acta Obstet Gynecol Scand 83(8): pp. 699-706.

6. Casper RF, Mitwally MF (2012) A historical perspective of aromatase inhibitors for ovulation induction. Fertil Steril 98(6): pp. 1352-1355.

7. Rajan RK, M SS, Balaji B (2017) Soy isoflavones exert beneficial effects on letrozole-induced rat polycystic ovary syndrome (PCOS) model through anti-androgenic mechanism. Pharm Biol 55: pp. 242-251.
8. Casper RF (2007) Aromatase inhibitors in ovarian stimulation. J Steroid Biochem Mol Biol 106 (1-5): pp. 71-75.

9. Kamath MS, George K (2011) Letrozole or clomiphene citrate as first-line for anovulatory infertility: a debate. Reprod Biol Endocrinol 9(1): pp. 86.

10. Maladkar M, Tekchandani C, Akshata Karchodi A (2020) Letrozole: an emerging array of hope for infertile women. Int J Reprod Contracept Obstet Gynecol 9(2): pp. 891-899.

11. Bailey CJ (1988) Metformin revisited: its actions and indications for use. Diabet Med 5(4): pp. 315-320.

12. Foretz M, Guigas B, Bertrand L, et al. (2014) Metformin: from mechanisms of action to therapies. Cell Metabol 20(6): pp. 953-966.

13. Podhorecka, M, Ibanez B, Dmoszynska A (2017) Metforminits potential anti-cancer and anti-aging effects. Postepy Hig. Med Dosw 71(0): pp. 170-175.

14. Stumvoll M, Nurjhan N, Perriello G, et al. (1995) Metabolic effects of metformin in non-insulin-dependent diabetes mellitus. N Engl J Med 333(1): pp. 550-554.

15. Pernicova I, Korbonits M (2014) Metformin-mode of action and clinical implications for diabetes and cancer. Nat Rev Endocrinol 10(3): pp.143-156.

16. Velazquez EM, Mendoza S, Hamer T, et al. (1994) Metformin therapy in polycystic ovary syndrome reduces hyperinsulinemia, insulin resistance, hyperandrogenemia, and systolic blood pressure while facilitating normal menses and pregnancy. Metabolism 43(1): pp. 647-654.

17. Nestler JE, Jakubowicz DJ, Evans WS, et al. (1998) Effects of metformin on spontaneous and clomiphene-induced ovulation in the polycystic ovary syndrome. N Engl J Med 338(26): pp. 1876-1880.

18. Practice Committee of the American Society for Reproductive Medicine. Fertil Steril 108 (3): 426-441.

19. Glueck CJ, Morrison JA, Friedman LA, et al. (2006) Obesity, free testosterone, and cardiovascular risk factors in adolescents with polycystic ovary syndrome and regularly cycling adolescents. Metabolism 55(4): pp. 508-514

20. Hahn S, Quadbeck B, Elsenbruch S, et al. (2004) Metformin, an efficacious drug in the treatment of polycystic ovary syndrome. Dtsch Med Wochenschr 129(19): pp. 1059-1064.

21. Palomba S, Orio F, Falbo A, et al. (2005) Prospective parallel randomized, double-blind, double-dummy controlled clinical trial comparing clomiphene citrate and metformin as the firstline treatment for ovulation induction in non-obese anovulatory women with polycystic ovary syndrome. J Clin Endocrinol Metab 90(7): pp. 4068-4074.

22. Rui Wang R, Mol BJ (2017) The Rotterdam criteria for polycystic ovary syndrome: evidence-based criteria?. Hum Reprod 32(2): pp. 261-264,.

23. Holzer $H$, Casper $R$, Tulandi $T$ (2006) A new era in ovulation induction. Fertil Steril 85(2): pp. 277-284. \& Homburg R (2008) Oral agents for ovulation induction-clomiphene citrate versus aromatase inhibitors. Hum Fertil (Camb) 11(1): pp. 17-22.

24. Rich-Edwards JW, Spiegelman D, Wreath M, et al. (2002) Physical action, weight file, and ovulatory issue fruitlessness. The study of disease transmission 13(1): pp. 184-190.

25. Hurley EG, Adams SR, Kalakota N, et al. (2017) The addition 
of metformin during ovulation induction with letrozole does not affect pregnancy outcome in infertile women with polycystic ovary syndrome. Fertil Steril 108(3): e246.

26. Elnashar A, Fouad H, Eldosoky $M$ et al. (2006) Letrozole induction of ovulation in women with clomiphene citrateresistant polycystic ovary syndrome may not depend on the period of infertility, the body mass index, or the luteinizing hormone/follicle-stimulating hormone ratio. Fertil Steril 85(2): pp. 511-513.

27. Badawy A, Mosbah A, Shady M (2007) Anastrozole or letrozole for ovulation induction in clomiphene-resistant women with polycystic ovarian syndrome: a prospective randomized trial, Fertil Steril. 89 (5): 1209-1212.

28. Nupur N, Mahua B, Amit T, et al. (2011) Experience of using letrozole as a first-line ovulation induction agent in polycystic ovary syndrome (PCOS). Al Ameen J. Med. Sci. (AJMS) 4(1): pp. 75-79.

29. Mitwally MFM, Casper RF (2001) Single-dose administration of the aromatase inhibitor, letrozole: a simple and convenient effective method of ovulation induction. Fertil Steril 76 (Suppl. 1): S94-S95.

30. Al-Omari WR, Sulaiman WR, Al-Hadithi N (2004) Comparison of two aromatase inhibitors in women with clomipheneresistant polycystic ovary syndrome. Int J Gynaecol Obstet 85(3): 289-291.

31. Atay V, Cam C, Muhcu M, et al. (2006) Comparison of letrozole and clomiphene citrate in women with polycystic ovaries undergoing ovarian stimulation. J Int Med Res 34(1): pp. 73-76.

32. Begum MR, Ferdous J, Begum A, et al. (2009) Comparison of the efficacy of aromatase inhibitor and clomiphene citrate in induction of ovulation in polycystic ovarian syndrome. Fertil Steril 92(3): pp. 853-857.

33. Sohrabvand F, Ansari SH, Bagheri M (2006) Efficacy of combined metformin- letrozole in comparison with metforminclomiphene citrate in clomiphene-resistant infertile women with the polycystic ovarian disease. Hum Reprod 21(6): pp. 1432-1435.

34. Buzdar AU, Robertson JF, Eiermann W, et al. (2002) An overview of the pharmacology and pharmacokinetics of the newer generation aromatase inhibitors anastrozole, letrozole, and exen- mestrane. Cancer 95(9): pp. 2006-2016.

35. Fleming R, Hopkinson ZE, Wallace AM, et al. (2002) Ovarian function and metabolic factors in women with oligomenorrhea treated with metformin in a randomized, double-blind placebocontrolled trial. J Clin Endocrinol Metab 87(2): pp. 569-574.

36. Johnson NP, Stewart AW, Falkiner J, et al. (2010) PCOSMIC: a multicentre randomized trial in women with Polycystic Ovary Syndrome evaluating Metformin for Infertility with Clomiphene. Hum Reprod 25(7):1675-1683.

37. Lord J, Thomas R, Fox B, et al. (2006) The effect of metformin on fat distribution and the metabolic syndrome in women with polycystic ovary syndrome-a randomised, double-blind, placebo-controlled trial. BJOG 113(7): pp. 817-824.

38. Ng EH, Wat NM, Ho PC. Effects of metformin on ovulation rate, hormonal, and metabolic profiles in women with clomiphene-resistant polycystic ovaries: a randomized, doubleblinded placebo-controlled trial. Hum Reprod 16(2): pp. 16251631.

39. Karimzadeh MA, Javedani M (2010) An assessment of lifestyle modification versus medical treatment with clomiphene citrate, metformin, and clomiphene citrate-metformin in patients with polycystic ovary syndrome. Fertil Steril 94(1): pp. 216-220.

40. Mohsin R, Saeed A, Baig MM, et al. (2019) Role of Letrozole and Metformin Vs Letrozole Alone in Ovulation Induction in Patients of Polycystic Ovarian Syndrome. PJMHS 13(1): 350-352.

41. Liu C, Feng G, Huang W, et al. (2017) Comparison of clomiphene citrate and letrozole for ovulation induction in women with polycystic ovary syndrome: a prospective randomized trial. Gynecol Endocrinol 33(11): pp. 872-876.

42. Elgafor IA (2013) Efficacy of combined metformin-letrozole in comparison with bilateral ovarian drilling in clomipheneresistant infertile women with polycystic ovarian syndrome. Arch Gynecol Obstet 288(1): pp. 119-123.

43. Davar R, Javedani M, Fallahzadeh MH (2011) Metforminletrozole, in comparison with Metformin-clomiphene citrate in clomiphene-resistance PCOS patients undergoing IUI. Iran J Reprod Med 9(1): pp. 31-36.

44. Johnson NP, Stewart AW, Falkiner J, et al. (2010) PCOS MIC: a multi-center randomized trial in women with Polycystic Ovary Syndrome evaluating Metformin for Infertility with Clomiphene. Hum Reprod 25(7):1675-1683. 